\title{
Aspects of higher training in emergency medicine
}

\author{
D A Kilroy
}

Postgrad Med J 2003;79:458-462

Correspondence to: Dr Darren A Kilroy,

Emergency Department, Sheffield Children's Hospital, Western Bank Sheffield S10 2TH, UK. dakilroy@doctors.org.uk

Submitted

16 December 2002

Accepted

18 February 2003
Objectives: To devise and develop a structured questionnaire addressing important issues relating to specialist registrar training in emergency medicine in the UK, and to then administer this questionnaire nationally to higher trainees in order to establish current practice and opinion regarding those issues. Methods: Informal interviews with current trainees were undertaken to identify themes which might be of wider importance in relation to training. The transcriptions were incorporated into a discussion questionnaire which was circulated to other trainees and to members of the Joint Committee on Higher Training in Accident and Emergency. A postal survey was developed from this draft and distributed to all trainees currently registered with the Faculty of Accident and Emergency Medicine.

Results: The response rate was $75 \%$. Collective responses to certain aspects of training are demonstrated in order to reflect current practice and opinion among UK specialist registrars and to allow further debate.

Conclusion: Development of a structured questionnaire allows issues in relation to training in emergency medicine to be assessed. The findings of the survey allow national data to be presented which will be of interest to trainees and trainers in the UK as well as overseas.
$\mathrm{H}$ igher specialist training in emergency medicine in the UK follows a template introduced in light of the Calman reforms, with a mandatory specialty "core" training period supplemented by key secondments. There is heavy emphasis on the role of the consultant in providing an effective educational environment for trainees. ${ }^{1}$ At the time of the reforms, proponents argued that more structured training would offset any reduction in actual clinical experience, and that making this training more targeted would improve its quality. In emergency medicine, the wide diversity of theoretical and practical knowledge required is reflected in the core curriculum published by the Joint Committee on Higher Training in Accident and Emergency, or JCHT(A\&E). Essential specialty secondments are completed during higher training or can, to a degree, be remitted against relevant prior experience at senior house officer level. Further "optional" secondments may be arranged to suit the aptitude of an individual trainee.

Central to the provision of a high quality training programme is the need for high quality appraisal and assessment of educational content and its delivery. Within the UK, the JCHT(A\&E) administers the regional training programmes to ensure that consistent quality standards are met through scheduled visits to emergency departments by representatives of the Committee, and via the Record of In-service Training Assessment (RITA) which is completed for all trainees annually.

The aspects of training addressed by these monitoring tools are decided centrally and, although important, there may be issues which trainees feel are not adequately addressed within the current RITA system, ${ }^{2}$ and there may be understandable reluctance to express concerns about training during a RITA assessment if it is perceived locally that such expression might prejudice a trainee's relationship with the trainer. It is also difficult to appreciate the national situation with regard to training in the specialty as the data generated by current quality monitoring procedures are not easily available.

Based on these issues, this study reports the design and development of a structured survey which reflects the aspects of specialist registrar training considered to be of most importance by trainees themselves. It goes on to report the findings of this survey when administered nationally, to allow discussion, comparison, and debate.

\section{METHODS}

The study was undertaken in stages. A series of informal interviews was undertaken with specialist registrars from a range of UK training deaneries, each of whom worked at a different unit, to develop awareness of themes which might be of relevance as part of a national survey. A draft survey proforma was then constructed and circulated for comment to a different group of higher trainees as well as to members of the JCHT(A\&E). As a result of comments received, a final draft was developed and circulated to all specialist registrars currently registered with the Faculty of Accident and Emergency Medicine.

\section{Informal interviews and themes}

Informal discussion was considered the most appropriate way to identify and develop issues for the survey. Ten specialist registrars, each of whom had been in post for at least six months, were interviewed. The themes which arose from the informal interviews were transcribed using established principles in order to maximise the reliability of the exercise. ${ }^{3}$ Aspects of training which were mentioned by trainees were grouped under headings relating to conditions of work, teaching received, teaching commitments and senior support, and the number of times these aspects arose was recorded as accurately as possible in order to allow generation of draft questions for the survey.

\section{Draft questionnaire}

A survey proforma was devised, and circulated for comment to 10 trainees not involved in the first round of interviews. The draft was also circulated to members of the JCHT(A\&E) to ensure that the survey questions could be seen and critiqued by the national training body. As a result of feedback received from trainees and committee members, some questions were expanded or added and a final proforma developed. The aim was to ensure that the questionnaire would take no longer

Abbreviations: FFAEM, Fellowship of the Faculty of Accident and Emergency Medicine; JCHT(A\&E), Joint Committee on Higher Training in Accident and Emergency; RITA, Record of In-service Training Assessment 


\section{Box 1: Questionnaire}

Higher training in emergency medicine

Thank you for taking the time to complete this questionnaire. It is designed to be simple. Please answer ALL the questions: this study is anonymised and there is no need to give any personal or regional information.

After completion, please return in the reply-paid envelope provided.

If you have any queries about the study or this questionnaire, please email or telephone.

Your responses will be important in providing an overview of aspects of higher training in UK emergency medicine.

\section{A Kilroy}

\section{Questionnaire}

1. Please indicate, rounded to the nearest hour, the time when direct consultant presence ends on the department shop floor. Use an average weekday as your example. Round up to the next nearest whole hour (for example, if 1725 put 1800).

2. Please indicate, to the nearest half hour, how many hours of formal, protected teaching time you receive on average per week (for fortnightly teaching, please calculate the pro rata weekly amount).

3. Please indicate whether or not you receive formal timetabled teaching on the following areas of the training syllabus (to be answered yes/no).
A. Clinical audit
B. Critical appraisal
C. Management topics
D. Specialist clinical topics
E. Skills of peer appraisal
F. Equal opportunities/interview skills
$G$. Medical ethics issues
$\mathrm{H}$. Design of teaching programmes

4. Please indicate your "status" in each of the following areas of skills-based life support $(P=$ provider; $I=$ instructor; $\mathrm{N}=$ neither).

A. ALS [Advanced Life Support]

B. ATLS [Advanced Trauma Life Support]

C. APLS [Advanced Paediatric Life Support]

D. MIMMS [Major Incident Medical Management and Support]

E. PHTLS [Prehospital Trauma Life Support]

5. Are you actively involved in an original research project at this time (do not include audit projects or supervised senior house officer [SHO] studies)?

6. Regarding the teaching of other departmental staffwhich of the following groups, if any, do you formally teach? (to be answered yes/no)
A. Departmental SHOs
B. Nursing staff
C. Medical students

7. Would you say you are generally satisfied with the information you receive from the JCHT(A\&E) in relation to current training issues?

8. Would you say that you are generally satisfied with the information you receive from the Faculty in relation to the exit FFAEM [Fellowship of the Faculty of Accident and Emergency Medicine] examination and its requirements?

9. Using the rating scale below, please mark a position from 1 (most satisfied) to 10 (least satisfied) in relation to the level of support and feedback you feel you receive from your current trainer.

1 (most) 2345678910 (least)

That completes the questionnaire. Thank you again for your assistance. Please now return the three answer sheets in the reply-paid envelope.
Table 1 Areas of teaching formally regularly timetabled into the programme

\begin{tabular}{lll}
\hline Topic & $\begin{array}{l}\text { Supported } \\
(\%)\end{array}$ & $\begin{array}{l}\text { Unsupported } \\
(\%)\end{array}$ \\
\hline Clinical audit (design/presentation) & $69(39)$ & $107(61)$ \\
Critical appraisal & $164(93)$ & $12(7)$ \\
Management topics & $153(87)$ & $23(13)$ \\
Clinical topics taught by specialists & $160(91)$ & $16(9)$ \\
\hline
\end{tabular}

Table 2 Is formal teaching received on the following at some stage in the training?

\begin{tabular}{lll}
\hline Topic & Yes (\%) & No (\%) \\
\hline Appraisal skills & $79(45)$ & $97(55)$ \\
Equal opportunities/interview skills & $67(38)$ & $109(62)$ \\
Medical ethics issues & $67(38)$ & $109(62)$ \\
Design of a teaching programme & $33(19)$ & $143(81)$ \\
\hline
\end{tabular}

than 10 minutes to complete yet would address all the relevant issues identified ( see box l).

\section{National survey}

All current higher trainees registered with the faculty were sent a copy of the questionnaire to their current registered address together with a reply-paid envelope. Publicity for the survey was achieved via the Emergency Medicine Journal, the BAETA (national trainees) meeting of 2001, and the Faculty Annual Scientific Meeting of 2001. The survey was anonymised. Completed surveys were assimilated to determine current practice and opinion on the range of issues addressed

\section{RESULTS}

Of 235 questionnaires distributed, 176 were returned, giving a response rate of $75 \%$.

Results for the survey questions are shown in figs $1-6$ and tables $1-4$. Where a particular question was not answered by all respondents, this is indicated.

Table 3 Provider or instructor status in recognised life support

\begin{tabular}{lll}
\hline Course & Provider (\%) & Instructor (\%) \\
\hline ALS & $90(51)$ & $70(40)$ \\
ATLS & $113(64)$ & $53(30)$ \\
APLS & $106(60)$ & $58(33)$ \\
MIMMS & $32(18)$ & $11(6)$ \\
PHTLS & $21(12)$ & $9(5)$ \\
\hline
\end{tabular}

ALS, Advanced Life Support; ATLS, Advanced Trauma Life Support; APLS, Advanced Paediatric Life Support; MIMMS, Major Incident Medical Management and Support; PHTLS, Prehospital Trauma Life Support.

Table 4 Formal involvement of higher trainees in teaching other healthcare staff

\begin{tabular}{lll}
\hline Teaching & Yes (\%) & No (\%) \\
\hline Teaching of departmental SHOs & $105(60)$ & $71(40)$ \\
Teaching of nursing staff & $44(25)$ & $132(75)$ \\
Teaching of medical students & $80(45)$ & $96(55)$ \\
\hline SHO, senior house officer. & & \\
\hline
\end{tabular}




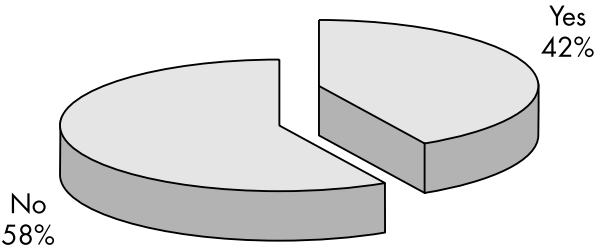

Figure 1 Active current involvement in original research $(n=174)$.

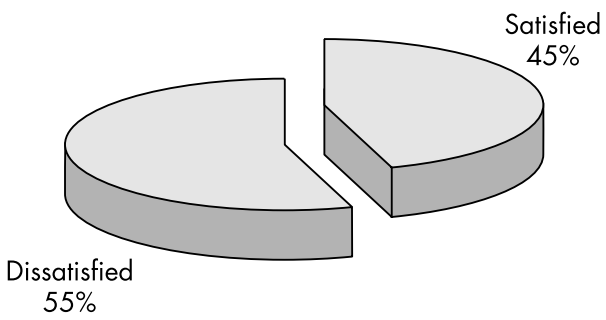

Figure 2 Satisfaction of trainees with the information received from the JCHT(A\&E) in relation to current training issues and the curriculum $(n=176)$.

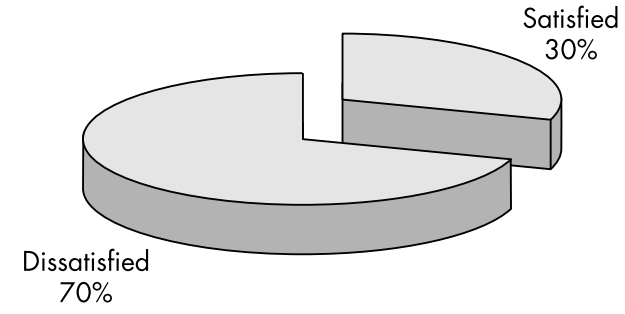

Figure 3 Satisfaction of trainees with the guidance received to the FFAEM examination and its requirements $(n=176)$.

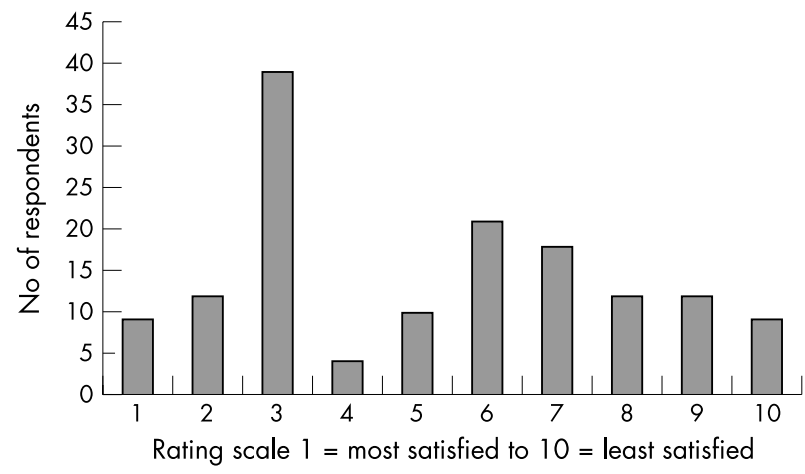

Figure 4 Perception of level of support and feedback received from current trainer $(n=146)$.

\section{DISCUSSION}

The aspects of training addressed by this survey reflect those issues considered most important by higher trainees themselves. Some of them are covered, in part, by data collected during RITA assessments. In a study such as this, great care must be taken to ensure that the questions do not merely reflect those issues which are perceived to be deficient in training, which is why the questionnaire design has been clearly described, and the initial interviews are fundamental in this respect. Small scale interviews are commonly used to yield data which are expanded through a survey of the population of interest, and the initial interview cohort of 10 trainees is a typical number. Specific direction was given to participants that they should reflect on those aspects of their training which they considered both good and bad and to express each of these. Keywords such as "shop floor", "teaching", and

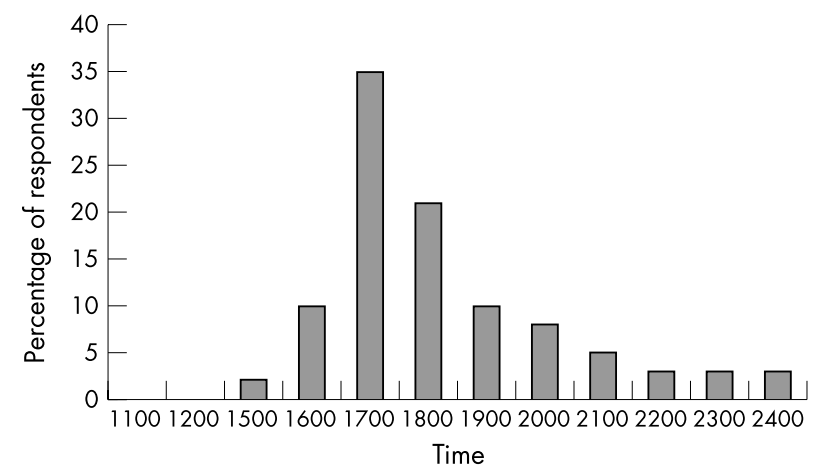

Figure 5 Time when direct consultant presence ends on shop floor $(n=176)$.

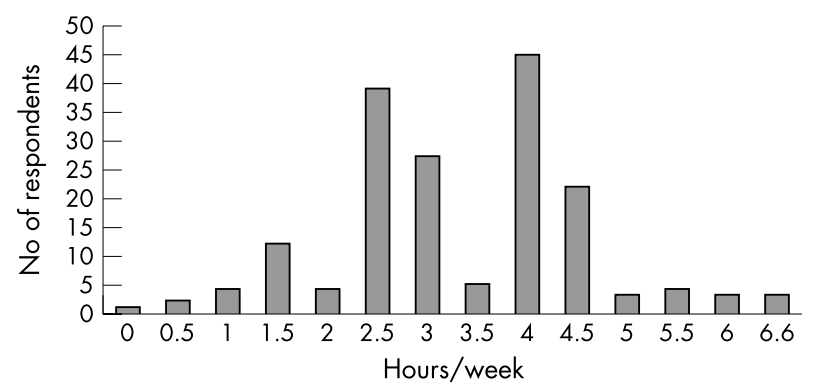

Figure 6 Hours of protected formal regional teaching received each week $(n=176)$.

"study leave" allowed themes to be developed and utilised in planning the survey. Transcription of themes into a question set is the area of the study most prone to problems with validity, and a balance must be struck between resource constraints and the need to achieve responses which best reflect the concerns raised in the initial interviews. The aim of presenting the draft survey to a different set of trainees was to achieve balance in the questions set; by also allowing comment from the consultant members of the JCHT(A\&E), the external validity of the survey was maximised and, importantly, the situation avoided whereby a national survey was distributed which had not been examined by the body responsible for training in the specialty.

The anonymity of the survey may have allowed trainees to be more frank in their opinion of certain training issues than they might feel comfortable with as part of RITA assessment. There is some, though limited, evidence apart from anecdote that this is actually the case, although naturally there may be reluctance to discuss issues locally from time to time. The current education and training support system aims to allow specific problems to be addressed and this was not an area which this survey was designed to examine.

The information gained through departmental visits by JCHT(A\&E) members is based on a standard report form available from the faculty website, but visits do not always involve the actual trainee in post at the time of the visit: in some cases, for logistical reasons, senior house officers or staff grade doctors are interviewed during the visit, and their comments may well not reflect the training concerns of the specialist registrar.

Themed aspects of the most important results of the study are discussed below.

\section{Senior support and supervision}

The balance between valuable clinical experience and excessive workload is delicate in educational terms. The quality of training which shop floor work can provide is variable and unstructured and the presence of senior support can be crucial 
in providing a rich experiential learning environment. Many departments have made significant alterations to shift patterns at various grades of staff to comply with the requirements of working time directives. Emergency medicine has very individual workforce planning requirements that can be difficult to align to the national guidelines laid down for junior medical staff: the presence of a consultant during shop floor working is valued by trainees, especially if this presence extends into the "unsocial" hours, and while the results demonstrate a broad spread of time which does attract direct supervision, many trainees will find their support ending in the early evening, when many departments begin to experience their most intense work pressures. Conversely, the fact that some trainees were able to report direct senior support until midnight may well reflect the staffing resources that are available at that unit, although it does not follow that large departments provide better out-of-hours supervision. The tensions inherent in obliging consultants to undertake enhanced "out-of-hours" cover have recently been well demonstrated in the rejection of the new consultants" contract, and the results of this study add weight to the call for significant increases in consultant numbers within the specialty to improve the quality of training for junior staff and clinical care for the public.

\section{Regional teaching programme}

Key learning issues for emergency medicine-critical appraisal, management, and clinical topics - are well covered in regional teaching. What is more difficult to measure is the quality of a teaching programme. On the basis that the exit Fellowship of the Faculty of Accident and Emergency Medicine (FFAEM) examination displays a pass rate of around $85 \%$ it can be inferred that standards are generally high. A consultant presence at teaching meetings is valued very highly by trainees in any discipline as it adds credibility to the learning and allows important extra perspectives to be discussed, but the considerable logistical efforts involved in providing this presence will again only be resolved with significant increases in senior staff resources.

The fact that only a minority of trainees had received teaching on the design of a teaching programme is of concern; emergency medicine has a heavy reliance on the service provision of senior house officers, and their education is fundamental to high quality clinical care as well as providing them with sound personal development. ${ }^{4}$ This is an aspect of specialist registrar training which could, arguably, be considered mandatory within the teaching curriculum. Current proposals to reform the senior house officer grade, ${ }^{5}$ with the prospect of four month attachments to accident and emergency departments in place of the current six, will place an even greater emphasis on high quality and focused teaching and may force the specialty to look at new ways of learning for junior staff. Likewise, the fact that over half of respondents reported no training in appraisal skills must be viewed seriously in light of the increasingly important role of workplace appraisal ${ }^{6}$; this again warrants attention.

\section{Issues relating to the trainer}

The role of the trainer and, specifically, the relationship which exists with the trainee, is crucial in specialist registrar development, and the whole concept of mentoring and support is highly topical. ${ }^{7}$ Difficulties in maintaining a productive working relationship can be extremely stressful for all concerned, and can profoundly affect learning, clinical competence, and career choice. The JCHT(A\&E) is occasionally made aware of circumstances in which there has been a fundamental breakdown in the trainee/trainer relationship, but this should represent the failure of local resolution involving both parties in conjunction with the regional programme director and the postgraduate dean. Concerns about the trainee/trainer relationship are arguably one of the main areas likely to be evasively dealt with in RITA assessment, where there may be considerable reluctance to divulge a problem with the trainer or, of course, trainee. The lack of evidence that this is the case probably further reflects under-reporting of the problem. Tensions such as these will always be present in professional environments and this must be accepted, as must the fact that there will be occasional local problems for which deaneries have an established procedure.

\section{Availability of national training advice}

One of the more disappointing findings of the study was the fact that the majority of trainees felt that they receive insufficient guidance from the faculty with relation to the exit FFAEM examination. Likewise, there is apparent dissatisfaction with the information provided by the JCHT(A\&E) in relation to training requirements. This may well be amenable to improved online resources, and in this respect the faculty website will prove crucial. Anecdotally, "worked examples" from a previous diet of the examination would be welcome, as would clearer information regarding the practical requirements of entry to the examination, which is administered separately by the Intercollegiate Board. It is fair to say that, in comparison to the web pages of other colleges, the faculty's own do appear rather staid, but it remains the responsibility of individual trainees to seek clarification regarding any queries or concerns they may have, and in this capacity the trainer is vitally important. There is also readily available advice from the relevant faculty officers, and the boards of the faculty all carry trainee representation.

\section{Miscellaneous training issues}

There is excellent national activity in relation to the core "life support" programmes of Advanced Life Support, Advanced Trauma Life Support, and Advanced Paediatric Life Support; the relatively lower prevalence of Major Incident Medical Management and Support activity reflects its relative newness, but it may well assume ever greater relevance as world events unfold. Prehospital life support programmes tend to attract those with a special interest in the field, and general practitioners involved in "BASICS" schemes play a vital part here. For most trainees, the "core" courses will cover the necessary skills to manage prehospital emergencies, and there is a need to balance course attendance with time and financial constraints. What is not in doubt is that these courses have a vital part to play, ongoing development of their style and content (for example, the shift to modular teaching which will occur in the Advanced Life Support course in 2003) should ensure their continued relevance. Adequate resources must be allocated to ensure that all trainees attend and, ideally, teach on the "core" courses as part of their professional development and in the interests of high quality service provision.

The balance of those involved or not involved in original research projects exemplifies the need to maintain a broad view of its value: an aspect of RITA assessment often previously mentioned anecdotally by trainees was the perceived over-reliance on the demonstration of research activity. The important issue is to encourage high quality, well supported research in those with natural aptitude while recognising that the ability to effectively appraise the literature and be aware of best practice in research methodology is of greater value to trainees as a whole.

\section{CONCLUSION}

The development of a structured questionnaire based on initial interviews, development of themes, and refinement through draft peer review allows current opinion on a range of issues considered important by current specialist registrars to 
be sought. The findings allow local comparison and discussion. The results of this study demonstrate that higher trainees in emergency medicine in the UK is generally well structured and satisfactory, but support the claim that, for us to provide best quality training for the future in this frontline specialty, there must be a significant expansion in consultant numbers and close attention to the provision of effective and useful resources for current trainees.

\section{ACKNOWLEDGEMENTS}

Gerardine Beckett (Faculty of Accident and Emergency Medicine) provided invaluable administrative assistance; Jonathan Marrow, Chair of the JCHT(A\&E) provided enthusiastic support for the study.

Postage costs were met by the Faculty of Accident and Emergency Medicine.
Author's affiliation

D A Kilroy, Trainees' Representative to the Joint Committee on Higher Training in Accident and Emergency Medicine, Faculty of Accident and Emergency Medicine

\section{REFERENCES}

1 Department of Health. A guide to specialist registrar training. 2nd Ed. London: DoH, 1997.

2 Milligan DW, Hutchinson LR. Effects of the Calman reforms: a two year review. Arch Dis Child 1999;80:84-7.

3 Krippendorf K. Content analysis - an introduction to its methodology. Beverly Hills, CA: Sage, 1980

4 Oxley J, ed. SCOPME. Teaching hospital doctors and dentists to teach. London: Standing Committee on Postgraduate Medical Education, 1994 5 Department of Health. Unfinished business, 2002 (available at:

www.doh.gov.uk).

6 Department of Health. NHS appraisal scheme, 2002 (available at: www.doh.gov.uk)

7 Roth LM, Schenk M, Bogdwic SP. Developing clinical teachers. Med Educ 2001;35:428-30.

\section{Readers' favourite}

\section{Top 10}

Click on the "Top 10" button on the homepage

to see which are the best read articles each month

www.postgradmedj.com 